\title{
Use of Clomiphene for Infertility in the Polycystic Ovary Syndrome
}

\author{
N Jahan ${ }^{1}$, B H N Yasmeen ${ }^{2}$, M B Parvin ${ }^{3}$, S Akhter ${ }^{4}$, S Yeasmin ${ }^{5}$
}

${ }^{1}$ Dr. Naseem Jahan Associate Professor Dept. of Obs and Gynae Dinajpur Medical College

${ }^{2}$ Prof. Dr. B H Nazma Yasmeen

Professor and Head

Dept. of Paediatrics

Northern International Medical College

${ }^{3}$ Dr. Mosammat Bilkis Parvin Assistant Professor

Dept. of Obs and Gynae MH Samorita Medical College

${ }^{4}$ Dr. Shirin Akhter Assistant Professor Dept. of Obs \& Gynae M H Samorita medical college

${ }^{5}$ Dr. Salma Yeasmin Assistant Professor Dept. of Obs and Gynae Holy Family Red Crescent Medical College

Correspondence Dr. Naseem Jahan Associate Professor Dept. of Obs and Gynae Dinajpur Medical College

\section{Abstract}

Background : The polycystic ovary syndrome is a common cause of infertility. Clomiphene is the current first-line infertility treatment in women with the polycystic ovary syndrome.

Objective : To observed effect of clomiphene therapy in infertile women with polycystic ovary syndrome.

Methodology : In this cross-sectional study we enrolled 210 infertile women aged $25-35$ years diagnosed as polycystic ovary syndrome. Participants who had normal urine cavity and sperm concentration of at least 20 million/ml of her husband were prescribed clomiphene for 6 months. Medication was discontinued when pregnancy was confirmed and participants were followed until delivery.

Results : After 6 months treatment 85(40.5\%) patient was conceived. Live birth was $44(20.9 \%)$ of 210 subjects. Among pregnancies multiple (twin) birth was $12(5.7 \%)$. First trimester pregnancy loss was $41(19.5 \%)$. After having 6 months of therapy there was no pregnancy in $125(59.5 \%)$ patients.

Conclusions : Clomiphene is safe and cost effective medicine in achieving live birth in infertile women with polycystic ovary syndrome.

Key words : Clomiphene, polycystic ovary syndrome, infertility.

\section{Introduction}

Polycystic ovary syndrome is one of the most common endocrine disorders, affecting about 5$15 \%$ of women of reproductive age. ${ }^{1,2}$ The polycystic ovary syndrome, which is diagnosed on the basis of hyperandrogenism, oligoovulation with associated oligomenorrhea, and polycystic ovaries on ultrasonography, affects 5 to $10 \%$ of reproductive-age women ${ }^{3}$ and is the most common cause of anovulatory infertility ${ }^{4}$ and early pregnancy loss. ${ }^{5}$ The cause of polycystic ovary syndrome is not fully understood, but evidence of a genetic component has been recognised in family and twin studies. ${ }^{6}$ Oligo-ovulation or anovulation in women with polycystic ovary syndrome is a major cause of infertility, and such women might require ovulation induction or assisted reproductive technology to become pregnant. ${ }^{7}$ Although the syndrome is a complex reproductive metabolic disorder, the hypothalamic pituitary axis has been the target of first-line ovulation induction therapy. Clomiphene citrate, a selective estrogen-receptor modulator that antagonizes the negative feedback of estrogen at the hypothalamus with a consequent increase in ovarian stimulation by endogenous gonadotropin, has been used for this indication for decades. Along with its advantages it has drawbacks as well, low live birth rate $^{5}$, a relatively high multiple pregnancy rate and an undesirable side-effect profile, including mood changes and hot flushes. ${ }^{5}$ Serious adverse event of this medicine is haemorrhagic corpus luteum cyst, hyper sensitivity reaction, back pain. Serious adverse events before birth were pregnancy loss after 12 weeks, ectopic pregnancy and preterm labour.

\section{Methods}

During the period of $2009-2013$, a total of 210 participants $25-35$ years of age diagnosed as polycystic ovary syndrome by history, ultrasonographic findings, blood hormone analysis and other causes of infertility were enrolled in a private hospital. Participants who had normal urine cavity and sperm concentration of at least $20 \mathrm{million} / \mathrm{ml}$ of her husband were included in this study. Participants who treated hyperprolactinemia by bromocriptin, oligomenorrhea by progesterone therapy were also included in this study after completion of treatment. Participants who had history of taking ovulation inducing agents were excluded from the study. All the participants were 
counseled about ovulation induction, clomiphene therapy and its side effects. Unsuccessful pregnancy outcome was also informed as well. History of infertility and use of ovulation inducing medicine were recorded.

Participants were prescribed to take clomiphene citrate tablet (5mg) five consecutive days from the $3^{\text {rd }}$ day of menstruation. They were instructed to have intercourse every 2 to 3 days from the $6^{\text {th }}$ day after completion of 5 days medication. They also requested to maintain diary to keep records like last menstrual period, vaginal bleeding and symptoms like nausea, vomiting, abdominal cramp, back pain, headache and hot flush. Clomiphene citrate was given for at least 6 cycles and medication discontinued when pregnancy was confirmed by viability of fetus documented by ultrasonography and then they were referred for prenatal cheek up. ${ }^{8}$

\section{Results}

A total of 210 infertile women aged $25-35$ years diagnosed as polycystic ovary syndrome were enrolled in this study. Baseline characteristics of the study population has shown in Table-1.

$\begin{array}{lc}\begin{array}{l}\text { Table }- \text { I : Clinical, radiological and laboratory findings } \\ \text { Biometric features }\end{array} & \text { Mean } \\ \text { Age (year) } & 26.3 \pm 4.0 \\ \text { BMI } & 30.0 \pm 7.2 \\ \text { Waist circumference }(\mathrm{cm}) & 101.0 \pm 2.0 \\ \text { Ovarian volume }\left(\mathrm{cm}^{3}\right) & \\ \quad \text { Left ovary } & 14.9 \pm 5.2 \\ \quad \text { Right ovary } & 12.2 \pm 4.3 \\ \text { Fasting blood sugar (mg/dl) } & 82.0 \pm 7.6 \\ \text { LH: FSH- ratio } & >3\end{array}$

Participants who had normal urine cavity and sperm concentration of at least $20 \mathrm{million} / \mathrm{ml}$ of her husband were prescribed clomiphene for 6 months. Medication was discontinued when pregnancy was confirmed and participants were followed until delivery. A total of 85 (40.5\%) subjects became pregnant (conceived), of them pregnancy loss was 41 $(19.5 \%)$, first trimester termination was $25(11.9 \%)$ and second trimester termination was $16(7.6 \%)$. Main reasons for pregnancy loss were placenta previa, severe hypertension.IUD etc. After completion of study we found live birth was 44 $(20.9 \%)$, of them singleton was $32(15.2 \%)$ and twin was 12 (5.7). Live birth rate was higher among the women whose BMI was $<30 \mathrm{~kg} / \mathrm{m}^{2}$. (Table-2)
Table -II: Outcome of the therapy

Variable

n (\%)

Conception

$85(40.4)$

Pregnancy loss

$41(19.5)$

Live birth

Singleton

$32(15.2)$

Twins

Pregnancy loss

First trimester termination

$25(11.9)$

Second trimester termination

$16(7.6)$

Several adverse effects of clomiphene was found in the study cases. Among them nausea was found in majority of the cases $50(23.8)$. Most of the events were also found in normal pregnancy i,e nausea, vomiting, headache etc. All of them were subsequently controlled with advancement of pregnancy. One patient had hemorrhagic corpus luteum cyst was treated by laparotomy and cystectomy, 2 cases treated for severe back pain. Serious adverse event before birth were pregnancy loss after 12 weeks of gestation, preeclampsia, preterm delivery, antipartum haemorrhage, premature rupture of membrane. All above pregnancy complications / adverse effects of clomiphene were treated accordingly (Table 3).

\section{Table III : Adverse effects of clomiphene}

\section{Adverse effects}

n (\%)

Serious adverse effects

$$
\text { Hemorrhagic corpus luteum cyst }
$$

Back pain

Other adverse effects

Nausea

Stomach discomfort

$3(1.4)$

Vomiting

Back pain

Headache

$12(5.7)$

Hot Flashes

$15(7.1)$

Adnexal pain

$2(0.9)$

Mild preeclampsia

$10(4.7)$

\section{Discussion}

In our study, we found mean age of the study women was almost similar to other studies. ${ }^{5,9}$ Mean BMI was lower comparing other studies ${ }^{5,9}$ but the mean fasting blood glucose was similar to the study and ovarian volume was little higher comparing other study. ${ }^{5}$

In our study live birth was 44 (20.9) which indicates clomiphene works better in polycystic ovaries to ovulate and have 
conception. It is safe and less costly treatment that couple can enter into trial before having in vitro fertilisation ${ }^{3}$. Singleton live birth rate was lower in our study comparing other study. ${ }^{9}$

$\mathrm{BMI}<30 \mathrm{~kg} / \mathrm{m}^{2}$ showed increased live birth rate with clomiphene therapy. ${ }^{10,11}$ Rate of pregnancy loss was higher 41 (19.52\%) in this study due to inclusion of obese and elderly women. ${ }^{5}$

In our study pregnancy outcome was lower comparing other studies. ${ }^{5,9}$ The reason of lower pregnancy outcome was due to not done hysterosalpingography to confirm fallopian tube patency.

\section{Conclusions}

Use of clomiphene is safe and cost effective medicine in achieving live birth in infertile women with polycystic ovary syndrome.

\section{References}

1. Archer JS, Chang RJ. Hirsutism and acne in polycystic ovary syndrome. Best Pract Res Clin Obstet Gynaecol 2004;18:737-54. [PubMed]

2. Asuncion M, Calvo RM, San Millan JL, Sancho J, Avila S, Escobar-Morreale HF. A prospective study of the prevalence of the polycystic ovary syndrome in unselected Caucasian women from Spain. J Clin Endocrinol Metab 2000;85:2434-8. [PubMed]

3. Rotterdam ESHRE/ASRM-Sponsored PCOS Consensus Workshop Group. Revised 2003 consensus on diagnostic criteria and long-term health risks related to polycystic ovary syndrome. Fertil Steril. 2004; 81:19-25.

4. Hull MG. Epidemiology of infertility and polycystic ovarian disease: endocrinological and demographic studies. Gynecol Endocrinol, 1987;1:23545.

5. Legro RS, Barnhart HX, Schlaff WD, Carr BR, Diamond MP, Carson SA et al. Clomiphene, Metformin, or Both for infertility in the Polycystic Ovary syndrome. 2007;356:551-566.

6. Legro RS, Driscoll D, Strauss JF 3rd, Fox J, Dunaif A. Evidence for a genetic basis for hyperandrogenemia in polycystic ovary syndrome. Proc Natl Acad Sci USA 1998;95:14956-60. [PMC free article] [PubMed]

7. Rajashekar L, Krishna D, Patil M. Polycystic ovaries and infertility: our experience. J Hum Reprod Sci 2008;1:65-72. [PMC free article] [PubMed]

8. Boomsma CM, Eijkemans MJ, Hughes EG, Visser GH, Fauser BC, Macklon NS. A meta-analysis of pregnancy outcomes in women with polycystic ovary syndrome. Hum Reprod Update, 2006;12:673-83.

9. Legro RS, Brzyski RG, Diamond MP, Coutifaris C, Schlaff WD, Casson P, et al. Letrozole versus Clomiphene for Infertility in the Polycystic Ovary Syndrome. N Engl J Med. 2014;371(2):119-129

10. Bolumar F, Olsen J, Rebagliato M, Saez-Lloret L, Bisanti L, Body mass index and delayed conception: a European multicenter study on infertility and subfecundity. Am J Epidemiol, 2000;151:1072-9.

11. Weiss JL, Malone FD, Emig D, Ball RH, Nyberg DA, Comstock CH, et al. Obesity, obstetric complications and cesarean delivery rate-a populationbased screening study. Am J Obstet Gynecol, 2004;190:1091-7. 